\title{
Morbidity and mortality profile of children admitted in pediatric department - A single center study
}

\author{
Pramila Ramawat ${ }^{1}$, Nilesh Jain ${ }^{2}$ \\ ${ }^{1}$ Assistant Professor, ${ }^{2}$ Associate Professor, Department of Pediatrics, MGM Medical College Indore
}

Background: Child morbidity and mortality is an issue of great concern for policy makers because in spite of good efforts still less than 5 years mortality rate is very high and many babies could not survive beyond infancy. Majority of pediatric deaths occurred due to preventable and treatable causes. An emphasis needed on early diagnosis and timely interventions in pediatric patients associated with high risk factors. Aims and Objectives: To study clinical spectrum, morbidity and mortality profile in hospitalized children and to evaluate association of clinicodemographic variable with outcome. Materials and Methods: A cross sectional study was conducted among 2315 patients admitted during study period to evaluate morbidity and mortality profile of patients in pediatric department. Data was collected between January to December 2018 and analyzed for demography, clinical profile including diagnosis, hospital and pediatric intensive care stay, management and outcome. Results: Mean age (mean \pm SD) reported was $42.35 \pm 35.85$ months. Under 5 years children were admitted in majority $(62.5 \%)$. Respiratory system (21.9\%) and nervous system diseases $(21.7 \%)$ were leading reasons for admission followed by gastrointestinal $(11.2 \%)$ and hematological disorders $(10.8 \%)$. Based on etiology infection was leading cause, most common infection in hospitalized children lower respiratory tract infections (19.5\%). Vaccine preventable diseases were present in $3.7 \%$ patients. $2.5 \%$ children admitted due to severe acute malnutrition (SAM). Nervous system diseases (18.2\%) associated with highest mortality followed by cardiac $(11.7 \%)$ and respiratory diseases $(11.2 \%)$ Mortality rate was $8.07 \%$. Significant association was found between gender, duration of PICU stay, condition at admission, under nutrition and severe anemia to outcome $(p<0.01)$. Conclusion: Early diagnosis and timely interventions can improve outcome in patients with co morbidities and high risk factors. Social awareness is very important to prevent gender discrimination. Emphasis on simple hygiene measures, vaccination and nutrition improvement can decrease the disease burden in pediatric population. Vaccine preventable diseases still occurring and needed hospitalization so strengthening of awareness program for vaccination required, especially in remote rural areas.
Access this article online

Website:

http://nepjol.info/index.php/AJMS DOI: 10.3126/ajms.v12i5.34453

E-ISSN: 2091-0576

P-ISSN: 2467-9100

Copyright (c) 2021 Asian Journal of Medical Sciences

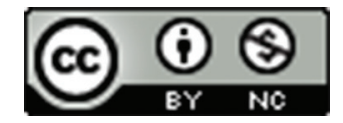

This work is licensed under a Creative Commons Attribution-NonCommercial 4.0 International License.

\section{INTRODUCTION}

Pediatric population is most important population for policy makers because it affects nation's future. According to WHO fact sheet in 2018 estimated 6.2 million children died below 15 years of age and underlying etiologies were preventable in majority of the cases. Under 5 years mortality was 5.3 million and causes were prematurity related complications, pneumonia, diarrhea, malaria, birth asphyxia and congenital anomalies. ${ }^{1}$

As per Census 2011, India, with a population of 121.1 crore, has 16.45 crore children in the age group 0-6 years and 37.24 crore in the age group 0-14 years which constitute 
$13.59 \%$ and $30.76 \%$ of the total population respectively. ${ }^{2}$ There has been substantial reduction in infant mortality rate (IMR) at national level from 46 in 2011 to 34 in 2016. Among the bigger States/UTs, IMR varies widely from 10 in Kerala to 47 in Madhya Pradesh. Under-five Mortality Rate (U5MR) estimated at 39 for 2016 at all India level varies significantly in rural and urban areas. Among the bigger States, U5MR varies from 11 in Kerala to 55 in Madhya Pradesh.,3

Under 5 children mortality and morbidity statistics in NFHS 4 survey showing health status of MP that was far behind to other states of India., ${ }^{2,3}$ High morbidity and mortality rate in children needed improvement in responsible factors for effective implementation of health programs. Madhya Pradesh has highest less than 5 mortality rate in India that's why it is essential to evaluate underlying causes to decide further action plans to improve health status of children. More than $50 \%$ deaths in children can be prevented by simple cost effective measures including routine vaccination of children and mothers, appropriate diet, safe water and food supply. Other important factor is provision of appropriate medical care by a trained health care provider whenever required. ${ }^{1}$

Infection is the most prevalent cause among pediatric intensive care admissions in developing countries. Diarrhea, respiratory illnesses, malaria and central nervous system (CNS) infections are still responsible for heavy burden of morbidity and mortality. In spite of great efforts by WHO, UNICEF, central and state governments for prevention of communicable diseases, India is still lagging behind goals.

This study was conducted to assess morbidity and mortality profile of hospitalized children to comprehend morbidity and mortality pattern of childhood illnesses for better understanding of childhood illnesses which require hospitalization and responsible for increased risk of mortality and underlying factors which can be prevented or improved. It may helpful in taking necessary steps to decide future policies to control pediatric disease burden.

\section{MATERIAL AND METHODS}

A cross sectional study was conducted among 2315 patients admitted in pediatric department of a tertiary care hospital in Central India. Study center had a large draining area and majority of patients are referred patients from peripheries and in critical condition. 10 bedded fully equipped PICU and 24 hour pediatric care facility is available where patients received from outpatient department, emergencies, referred from other hospital and post operative patients required PICU care.
Patients admitted in pediatric intensive care unit (PICU) and pediatric ward between January to December 2018, 1 month to 14 year of age were included in the study. Patients whose medical records were incomplete or relevant data was absent excluded. Patient admitted with more than one diagnosis, disease responsible for hospitalization considered as primary diagnosis. Diseases were classified according to WHO ICD - 10 (International statistical classification of disease) classifications.

Data collected from medical records of patients from hospital medical record section about etiology, admission type - emergency or elective, admission source - direct admission, referred or transferred patient from other department and various other parameters like primary disease, co morbidities, PICU stay, demographic profile and outcome were recorded in sheet with predesigned proforma. Collected data was analyzed for morbidity and mortality profile.

\section{Statistical analysis}

All data collected, compiled and analyzed with the help of SPSS 16 trial version. Descriptive and inferential statistics had used. Mean, ratio, proportion and rate were calculated. Results for continuous variable presented as mean \pm SD while categorical variables presented in numbers and percentage (\%). Chi square test used to show association between variables. Probability value $\leq 0.05$ was considered as statistically significant.

\section{RESULTS}

Present study found 2315 patients admitted in PICU and pediatric ward aged 1 month to 14 years during study period. Among these 2315 patients 187 patients expired, mortality rate was $8.07 \% .26$ patients were transferred in and 11 patients transferred out from department. Thirty four percent were referred patients, $78 \%$ were emergency admission (Table 1). 8.3\% patients received mechanical ventilation.

During study period majority of children admitted in pediatric department were under 5 years of age $(62.5 \%)$, out of them $30.06 \%$ were infants and $32.48 \%$ were 1 to 5 years of age. $37.45 \%$ patients were above 5 year of age. Mean (mean $\pm \mathrm{SD}$ ) age for hospitalization was $42.35 \pm 35.85$ months. Males $(58.13 \%)$ were in majority in comparison to females. Male: Female ratio ( $\mathrm{M}: \mathrm{F}$ ratio) was $1.39: 1$ in hospitalized children.

As shown in Table 2 maximum patients were admitted due to respiratory diseases $(21.9 \%)$. Most common cause for hospitalization was lower respiratory tract infections 
(19.7\%). Respiratory diseases were prominent reason for hospitalization but case fatality rate found to be low $(4.1 \%)$.

Nervous system diseases (21.7\%) were second leading cause, seizures $(9.3 \%)$ was most frequent reason for hospitalization followed by meningoencephalitis $(8 \%)$. CNS diseases found to be leading cause for mortality $(18.7 \%)$. Case fatality rate was $6.9 \%$.

Gastrointestinal system (11.2\%) was third system involved, mostly patients admitted due to acute gastroenteritis $(6.7 \%)$. Liver diseases were responsible for admission in 3.9\% cases including viral hepatitis, liver failure, chronic liver disease and cholestasis. Case fatality rate was $5.3 \%$.

Cardiac diseases were responsible for $5.7 \%$ cases, most common cause was congenital heart disease (CHD) and others were rheumatic heart disease and cardiomyopathy. Most common CHD was ventricular septal defect followed by tetralogy of fallot and patent ductus arteriousus. Case fatality rate was highest $(16.6 \%)$ in cardiac patients.

In hematological disorders $(10.8 \%))$, most common cause for hospitalization was anemia. Iron deficiency anemia was the leading anemia followed by sickle cell anemia and thalassemia. Other hematological diseases were idiopathic

\begin{tabular}{|c|c|c|c|}
\hline S. No. & Variable & & Number (\%) \\
\hline 1. & Total Admission & & 2315 \\
\hline 2. & Improved & & 1849 (79.9) \\
\hline 3. & Death & & $187(8.07)$ \\
\hline 4. & Left against med & al advise & $279(12)$ \\
\hline 3. & Referred patient & $\begin{array}{l}\text { Yes } \\
\text { No }\end{array}$ & $\begin{array}{c}791(34.1) \\
1524(65.8)\end{array}$ \\
\hline 4. & Transfer & $\begin{array}{l}\text { In } \\
\text { Out }\end{array}$ & $\begin{array}{c}26(1.1) \\
11(0.47)\end{array}$ \\
\hline 5. & Admission & $\begin{array}{l}\text { Emergency } \\
\text { Elective }\end{array}$ & $\begin{array}{c}1817(78.4) \\
498(21.5)\end{array}$ \\
\hline
\end{tabular}

thrombocytopenic purpura, leukemia and hemophilia. Case fatality rate was $6 \%$.

In renal system involved in $3.8 \%$ cases, patients admitted with chronic kidney disease $(1.1 \%)$, nephrotic syndrome $(0.9 \%)$ and others. Nutritional problems were found in $5.9 \%$ patients. Mostly patients admitted with primary diagnosis of severe acute malnutrition (SAM), others reasons were infantile tremor syndrome (ITS), pre ITS and rickets. Case fatality rate was high in patients with nutritional problems (13\%).

Poisoning was found in $4.5 \%$ cases, exposure route was ingestion $(100 \%)$, mostly accidental in nature. Case fatality rate due to poisoning was $5.7 \%$. Miscellaneous causes were diabetic ketoacidosis $(0.8 \%)$, foreign body inhalation $(0.7 \%)$, collagen vascular disorder $(0.4 \%)$, snake bite $(0.5 \%)$, scorpion sting and others.

Vaccines preventable diseases (3.7\%) reported during study period were tetanus, TBM, diphtheria, measles, rabies, hepatitis B and pertussis (Figure 1).

Table 3 shows that most common cause of admission in pediatric intensive care and pediatric ward was infections based on etiology. Lower respiratory tract infections (LRTI) were most common cause for hospitalization (19.5\%). Pneumonia $(12 \%)$ was prevalent LRTI. Other infections were acute gastroenteritis $(6.7 \%)$, septicemia $(4.1 \%)$, meningitis, malaria, dengue and others. Seizure $(9.3 \%)$ was second leading cause including epilepsy, febrile seizure and others. Anemia (8.2\%) was third reason and iron deficiency anemia, sickle cell anemia, thalassemia were common underlying etiologies. Meningoencephalitis (8\%) was fourth cause included bacterial, tubercular and viral meningoencephalitis. Congenital heart disease was fifth reason for admission $(5.2 \%)$ and also associated with high mortality rate. Other causes were poisoning (4.5\%), liver diseases (3.9\%), SAM $(2.6 \%)$, cerebral palsy $(1.9 \%)$ and others $(25.6 \%)$, mortality rate was very high $(30 \%)$ in SAM patients.

\begin{tabular}{|c|c|c|c|}
\hline System involved and disease & $\begin{array}{c}\text { Admission } \\
\text { Number }(\%)(\mathrm{N}=2315)\end{array}$ & $\begin{array}{c}\text { Death } \\
\text { Number }(\%)(n=187)\end{array}$ & Case fatality rate $(\%)$ \\
\hline Respiratory & 507 (21.9) & $21(11.2)$ & 4.1 \\
\hline CNS & $503(21.7)$ & $35(18.7)$ & 6.9 \\
\hline GIT & $260(11.2)$ & $14(7.4)$ & 5.3 \\
\hline Hematology & $250(10.8)$ & $15(8.02)$ & 6.0 \\
\hline Infection & $240(10.3)$ & $23(12.2)$ & 9.5 \\
\hline Nutrition & $138(5.9)$ & $18(9.6)$ & 13.0 \\
\hline CVS & $132(5.7)$ & 22 (11.7) & 16.6 \\
\hline Poisoning & $104(4.5)$ & $6(3.2)$ & 5.7 \\
\hline Renal & $89(3.8)$ & $7(3.7)$ & 7.8 \\
\hline Miscellaneous & $92(3.9)$ & $26(13.9)$ & 28.2 \\
\hline
\end{tabular}


In Table 4, monthly distribution of admissions and deaths. Admission rate was high in January, February, September and October months at time of season change while minimum admission was in August. Maximum deaths were noted in September (11.7\%) and minimum in April (5.8\%). Monthly mortality rate was highest in December $(12.2 \%)$ and lowest in April (6.0\%). Mean for hospitalization was 177 and for death mean was 15.58. Mean mortality rate was $8.4 \%$.

In present study outcome was evaluated in 2036 patients among these $90.81 \%$ patients improved and $9.1 \%$ patients expired. 278 patients left against medical advice (LAMA) so outcome could not be evaluated in them. Majority of hospitalized children were under 5 year

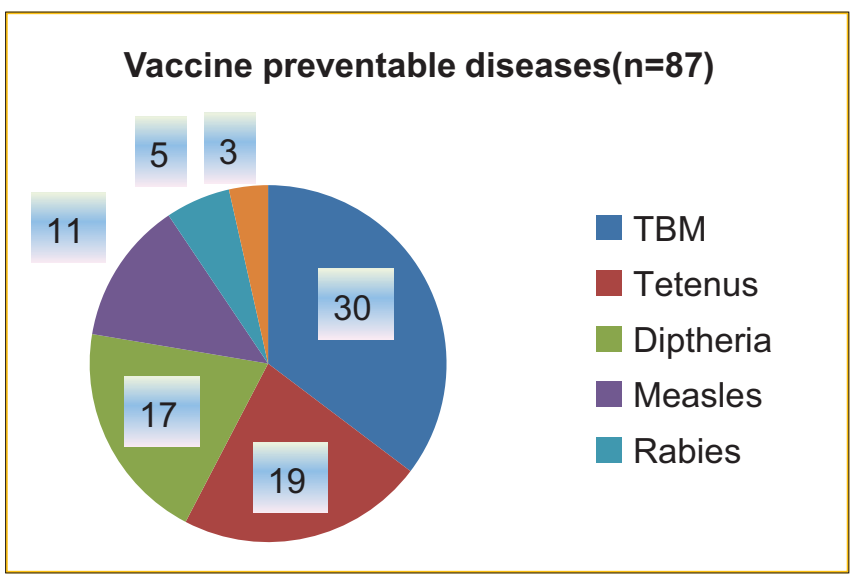

Figure 1: Vaccine preventable disease distribution

\begin{tabular}{|c|c|c|c|}
\hline S. No. & Etiology & $\begin{array}{l}\text { Numbers } \\
(\mathrm{N}=2315)\end{array}$ & Percentage \\
\hline 1. & $\begin{array}{l}\text { Lower respiratory tract } \\
\text { infection }\end{array}$ & 453 & $19.5 \%$ \\
\hline 2. & Seizure & 217 & $9.3 \%$ \\
\hline 3. & Anemia & 191 & $8.2 \%$ \\
\hline 4. & Meningoencephalitis & 186 & $8.0 \%$ \\
\hline 5. & Acute gastroenteritis & 156 & $6.7 \%$ \\
\hline 6. & Congenital heart disease & 122 & $5.2 \%$ \\
\hline 7. & Poisoning & 104 & $4.5 \%$ \\
\hline 8. & Septicemia & 95 & $4.1 \%$ \\
\hline 9. & Liver disease & 91 & $3.9 \%$ \\
\hline 10. & Severe acute malnutrition & 60 & $2.6 \%$ \\
\hline 11. & Cerebral palsy & 46 & $1.9 \%$ \\
\hline 12. & Others & 594 & $25.6 \%$ \\
\hline
\end{tabular}

of age contributed to $62.5 \%$ of pediatric mortality during study period while mortality rate was $8.08 \%$. Number of deaths was more in under 5 children due to their high number of hospitalization but no statistical significant difference $(\mathrm{p}=0.53)$ was found in both age groups (above and below 5 years) in outcome as shown in table 5. Male: female ratio (M: F ratio) was 1.39:1 in hospitalized children while 0.8: 1 in expired children. Admission rate was high for males but mortality rate was high for females $(10.4 \%)$ than males $(6.4 \%)$. Statistical significant gender difference $(p=0.001)$ was found in outcome (Table 5).

Severe anemia (as per WHO classification of anemia) correlated with poor outcome of patients. ${ }^{4}$ Serious condition of patients (hemodynamicaly unstable, altered sensorium, respiratory distress, cyanosis,) also associated with poor outcome. Association of co morbidities (malnutrition, severe anemia), condition on admission and duration of PICU stay with outcome was found to be strongly significant $(\mathrm{p}<0.01)$ as shown in Table 5 .

\section{DISCUSSION}

In the study admission rate in hospital was more for boys than girls. This was also shown in other studies - Adhikari et al. from Nepal and Saho B et al. (61.3\%)., Majority of males in admission also present in Shah and Mirdha's study. ${ }^{7,8}$ It may be due to still preference of boys over girls for care which also reflected in difference in mortality rate where females outnumbered. Mean age in present study was $3.5 \pm 2.9$ years while 4.3 years \pm 5 years were reported by Falludin et al. ${ }^{?}$

A total of $30.06 \%$ infants admitted in present study while $47.4 \%$ infants admitted in study by Haqu et al, and 50\% reported by Earen SK. ${ }^{10,11}$ In present study although under 5 children contributed to $62.5 \%$ of total mortality but no significant difference was found between both age groups (under and above 5 years) for admission and mortality. Number of deaths was more in under 5 years children due to their high number of hospitalization. Mortality rate for both groups were showing no statistical significant difference.

Table 4: Monthly distribution of hospitalized patients in study year

\begin{tabular}{|c|c|c|c|c|c|c|c|c|c|c|c|c|c|}
\hline Month & Jan. & Feb. & Mar. & April & May & June & July & Aug. & Sep. & Oct. & Nov. & Dec. & Mean \\
\hline Admission $(\mathrm{N}=2315)$ & 242 & 231 & 198 & 183 & 197 & 163 & 164 & 118 & 264 & 261 & 162 & 132 & 177 \\
\hline$(\%)$ & $10.4 \%$ & $9.9 \%$ & $8.5 \%$ & $7.9 \%$ & $8.5 \%$ & $7.0 \%$ & $7.0 \%$ & $5.0 \%$ & $11.4 \%$ & $11.2 \%$ & $6.7 \%$ & $5.7 \%$ & $7.6 \%$ \\
\hline Death $n=187$ & 16 & 17 & 14 & 11 & 12 & 15 & 17 & 14 & 22 & 18 & 15 & 16 & 15.58 \\
\hline$(\%)$ & $8.5 \%$ & $9.0 \%$ & $7.4 \%$ & $5.8 \%$ & $6.4 \%$ & $8.0 \%$ & $9.0 \%$ & $7.4 \%$ & $11.7 \%$ & $9.6 \%$ & $8.0 \%$ & $8.5 \%$ & $8.3 \%$ \\
\hline Mortality rate (\%) & 6.6 & 7.3 & 7.07 & 6.0 & 6.0 & 9.20 & 10.3 & 11.8 & 8.3 & 6.8 & 9.2 & 12.2 & 8.4 \\
\hline
\end{tabular}




\begin{tabular}{|c|c|c|c|c|c|}
\hline \multicolumn{2}{|c|}{ Clinicodemographic variables } & \multirow{2}{*}{$\begin{array}{c}\begin{array}{c}\text { Total patients } \\
\text { Numbers }(\mathbf{N}=\mathbf{2 0 3 6})\end{array} \\
1150(56.5 \%) \\
886(43.5 \%)\end{array}$} & \multirow{2}{*}{$\begin{array}{c}\text { Survived Numbers (\%) } \\
\text { (n- 1849) (90.8\%) }\end{array}$} & \multirow{2}{*}{$\begin{array}{c}\begin{array}{c}\text { Death Numbers (\%) } \\
\text { (n-187) }(9.2 \%)\end{array} \\
87(46.5 \%)\end{array}$} & \multirow{2}{*}{$\begin{array}{l}\text { P value } \\
0.001^{*}\end{array}$} \\
\hline Gender & $\begin{array}{l}M \\
F\end{array}$ & & & & \\
\hline Age & $\begin{array}{l}\leq 5 \text { years } \\
>5 \text { years }\end{array}$ & $\begin{array}{l}1282(62.9 \%) \\
754(37.1 \%)\end{array}$ & $\begin{array}{l}1171(63.3 \%) \\
678(36.7 \%)\end{array}$ & $\begin{array}{l}117(62.6 \%) \\
70(37.4 \%)\end{array}$ & $0.447^{\star *}$ \\
\hline $\begin{array}{l}\text { Serious condition on } \\
\text { admission }\end{array}$ & $\begin{array}{l}\text { Yes } \\
\text { No }\end{array}$ & $\begin{array}{l}853(41.9 \%) \\
1183(58.1 \%)\end{array}$ & $\begin{array}{c}699(37.8 \%) \\
1150(62.2 \%)\end{array}$ & $\begin{array}{l}155(82.9 \%) \\
32(17.1 \%)\end{array}$ & $0.001^{*}$ \\
\hline PICU stay & $\begin{array}{l}\leq 72 \text { hours } \\
>72 \text { hours }\end{array}$ & $\begin{array}{l}1361(66.8 \%) \\
675(33.2 \%)\end{array}$ & $\begin{array}{l}1254(67.8 \%) \\
595(32.2 \%)\end{array}$ & $\begin{array}{l}107(57.2 \%) \\
80(42.8 \%)\end{array}$ & $0.003^{*}$ \\
\hline Undernourished & $\begin{array}{l}\text { Yes } \\
\text { No }\end{array}$ & $\begin{array}{c}458(22.5 \%) \\
1578(77.5 \%)\end{array}$ & $\begin{array}{c}345(18.7 \%) \\
1504(81.3 \%)\end{array}$ & $\begin{array}{l}113(60.4 \%) \\
74(39.6 \%)\end{array}$ & $0.001^{*}$ \\
\hline Severe anemia & $\begin{array}{l}\text { Yes } \\
\text { No }\end{array}$ & $\begin{array}{l}326(16.0 \%) \\
1710(83.9)\end{array}$ & $\begin{array}{c}264(14.3 \%) \\
1585(85.7 \%)\end{array}$ & $\begin{array}{l}62(33.2 \%) \\
125(66.8 \%)\end{array}$ & $0.001^{*}$ \\
\hline
\end{tabular}

*The association is highly/ strongly significant for 1 degree of freedom at the 0.01 level of significance. **The association is not significant for 1 degree of freedom at the 0.05 level of significance

In this study respiratory system predominantly involved followed by CNS system for hospitalization. Most common cause based on etiology was infections followed by seizure and anemia. Study by Saho B et al also showed same results most common causes for admission were respiratory diseases and infections in their study, study by Shukla also showed infection as most common cause for admission and mortality. ${ }^{6,12}$ Roy RN reported respiratory infections $(22.2 \%)$, seizures $(12.68 \%)$, poisoning and accidents $(6.07 \%)$ were leading causes for hospitalization. ${ }^{13}$ In present study pneumonia, seizures and anemia were leading causes based on etiology for admission. Earen SK et al also found respiratory diseases, infections and CNS diseases as most common cause for admission. ${ }^{11}$

Pattern of diseases changed over time. In current study congenital heart disease (CHD) was predominant cardiac cause for hospitalization. Cases of CHD were increased may be due to easy availability of echocardiography and improved survival with better treatment facilities. Number of rheumatic heat disease patients decreased significantly over time due to changing life styles and increased use of antibiotics.

Pneumonia, diarrhea and malaria are predominant reason for high morbidity and mortality in children according to WHO fact sheet. ${ }^{14}$ In this study causes were different, neurological diseases was leading reason for mortality followed by cardiac diseases and infections. Reason may be it was a hospital based study where referred patients treated so morbidity and mortality pattern may be different.

According to WHO fact sheet in 2019, 5.2 million children under 5 year of age died due to preventable and treatable causes. Mortality decreased in older children and most common cause is trauma and accidents. ${ }^{14}$ Neurological diseases were leading reason for mortality in present study followed by infections and cardiovascular diseases while infection was most common cause in Shukla's study. ${ }^{12}$ Falludin et al reported that sepsis, pneumonia, CHF and hepatic encephalopathy were leading causes for mortality while sepsis, cardiac diseases and neurological diseases were reported by Sankar et al. ${ }^{9.15}$ LRTI, CNS infections and malnutrition were three leading causes of mortality according to Bucens et al. ${ }^{16}$ Mortality rate was $8.06 \%$ in this study, other studies with similar results were Reshma R P (mortality rate - 10.58\%), Mridha D (20\%) and Khilani (mortality rate $-6.7 \%$ ). ${ }^{8,17,18}$ Low mortality rate was reported by Saho (4.7\%) and Fallahudin (1.35\%).,9 Diarrhea, malnutrition and malaria were reported as common cause by Okechuknu AA. ${ }^{19}$ High mortality rate in present study was due to hospitalization of patients in critical condition, majority were referred patients and co morbidities (e.g. - under nutrition and anemia) were present.

Gender, under nutrition, anemia, duration of PICU stay and condition on admission were significantly associated with high mortality in present study. Mortality rate for girls was higher than boys in study by Onyiriuka AN. ${ }^{20}$ Similar results were found in this study. Desire B et al reported malnutrition is significantly associated with mortality in less than five years children. ${ }^{21}$

Vaccine preventable diseases are still prevalent in community as reported in current study. It suggests that immunization is still lagging behind expectations. NFHS - 4 surveys showed improvement in immunization rate but still coverage in remote areas is not optimum., ${ }^{2,3}$ The explanation could be lack of awareness in remote areas and 
not understanding importance of vaccination by people result in undue hospitalization and suffering on part of children.

Present study concluded that mortality is high in girls, morbidity and mortality both were higher in under 5 years children, infection is still a major cause for increased hospitalization including pneumonia and diarrhea. Emphasis on preventive measures needed including nutrition, immunization, improvement in hygiene and sanitation facilities.

\section{Limitations of the Study}

Limitation of present study were single centric and hospital based so it is suggested that future studies should be planned multi centric or community based long term studies to verify findings of current study.

\section{CONCLUSION}

Present study concluded that infection is prevalent reason for hospitalization and associated with high mortality. Early diagnosis and treatment may improve patient outcome especially in patient with co morbidities and risk factors. Female mortality rate is also high, social awareness required to decrease discrimination. Vaccine preventable diseases still prevalent so further emphasis on immunization awareness required specially in remote areas. Simple preventive measures like hand hygiene, nutrition, vaccination and sanitation facility can decrease significant disease burden in pediatric population.

\section{REFERENCES}

1. WHO fact sheet 2019 children: reducing mortality. https://www. who.int/news-room/fact-sheets

2. Dhirar N, Dudeja S., Khandekar J and Bachani D. Childhood Morbidity and Mortality in Inda - Analysis of National Family Health Survey 4 (NFHS - 4) Findings. Indian Pediatrics.2018; (4) 55:335-338.

https://doi.org/10.1007/s13312-018-1276-6

3. Indian Institute for Population Sciences (IIPS) and MoHFW. National Family Health Survey - 4. 2017. Available from: http:// rchiips.org/nfhs/pdf/NFHS4/ India.pdf. Accessed June 12, 2017.

4. Hemoglobin concentrations for the diagnosis of anemia and assessment of severity VMNIS | Vitamin and Mineral Nutrition Information System

https://www.who.int/vmnis/indicators/haemoglobin.pdf

5. Adhikari J, Balbase M and Bahl L. Demographic Profile and Childhood Morbidity pattern in Western Nepal. JNGMC.2014; 12(2).

https://doi.org/10.3126/jngmc.v12i2.14471

6. Sahoo B, Patnaik S, Mishra R and Jain MK. Morbidity pattern and outcome of children admitted to a paediatric intensive care unit of Eastern India. Int J Contemp Pediatr. 2017; 4:4869. https://doi.org/10.18203/2349-3291.ijcp20170694
7. Shah GS, Shah BK, Thapa A, Shah L and Mishra OP. Admission patterns and outcome in a pediatric intensive care unit in Nepal. Br J Med Med Res. 2014; 4(30):4939-4945. https://doi.org/10.9734/BJMMR/2014/10318

8. Mirdha D., Saha S., Gangule S and Bore K. A retrospective evaluation of morbidity pattern and outcome of patient admitted in pediatric intensive care unit in India. JMSCR. 2017; 05(11):30586-30590.

https://doi.org/10.18535/jmscr/v5i11.132

9. Fallahzadeh MA, Abdehou ST, Hassanzadeh J, Fallhzadeh F, Fallahzadeh $\mathrm{MH}$ and Malekmakan L. Pattern of in-hospital pediatric mortality over a 3-year period at University teaching hospitals in Iran. Indian J Crit Care Med. 2015; 19(6):311-315. https://doi.org/10.4103/0972-5229.158257

10. Haque $A$ and Bano S. Clinical profile and outcome in a pediatric intensive care unit in Pakistan. J Coll Phys Surg Pakistan. 2009; 19:534-535.

https://doi.org/10.5005/jp/books/10637_49

11. Earan SK, Dhandapani L, Arunagirinathan A and Kantamneni S. Clinical Spectrum and Epidemiological Profile of Patients Admitted to Pediatric Intensive Care Unit at a Tertiary Care Centre in South India. Int J Sci Stud. 2016; 4(3):187-191.

12. Shukla VV and Nimbalkar SM. Critical Analysis of PIM - 2 Score Applicability in a Tertiary Care PICU in Western India. International Journal of Pediatrics.2014; 703942. https://doi.org/10.1155/2014/703942

13. Roy RN, Shrivastav P, Das DK, Saha I and Sarkar AP. Burden of hospitalizes pediatric morbidity and utilization of beds in a tertiary care hospital of Kolkata India. Indian Journal of Community Medicine. 2012; 37(4):252-255.

https://doi.org/10.4103/0970-0218.103474

14. WHO.int/news room/fact sheet/detail children: Improving survival and well being.

https://www.who.int/news-room/fact-sheets

15. Sankar J, Chandel A, Dubey NK, Srinivas V and Shankar MJ. Do interventions in an ICU affect the pediatric ability of Pediatric index of mortality and pediatric index of mortality 2 score in a tertiary care hospital. Pediatr Crit Care Med. 2013; 14:e70-e76. https://doi.org/10.1097/PCC.0b013e31827127cd

16. Buccen IK, Reid A, Barello AC, Dwivedi V and Counahan M. Three year of pediatric morbidity and mortality at the national hospital in Dili, East Timor. J Pediatr Child Health. 2013; 49:1004-1009.

https://doi.org/10.1111/jpc.12305

17. Rashma RP, Remya S, Jayakumar C, Shanavas M, Manu R, Remya R, et al. Mortality Profile of Children Admitted to Intensive Care Unit of a Tertiary Care Hospital in Kerala, South India. Int J Med Clin Sci. 2018; 1(1):13-16.

18. Khilnani P, Sarma D, Singh R, Uttam R, Rajdev S, Makkar A, et al. Demographic profile and outcome analysis of tertiary level pediatric intensive care unit. Indian J Paediatr. 2004; 71:58791. https://doi.org/10.1007/BF02724117

19. Okachukwu AA and Nwalozie C. Morbidity and mortality pattern of admission into the emergency pediatric unit of University of Abuja Teaching hospital, Gwagwaleda, Nigeria J Med. 2011; 20:109-113.

20. Onyiriuka AN. Morbidity and mortality pattern of post neonatal pediatric medical admission in a large mission hospital in Benin city Nigeria. JMBR. 2005; 4(1):49-58. https://doi.org/10.4314/jmbr.v4i1.10668

21. Banga D, Baren M, Ssonko NV, Sikakulya FK, Tibambenda Y, 
Banga C, et al. Comorbidities and Factors associated with mortality among children under five years admitted with severe acute malnutrition in the nutritional unit of Jinia Regional Referral
Hospital Eastern Uganda. International Journal of Pediatrics. 2020; Article ID 7809412.

https://doi.org/10.1155/2020/7809412

\section{Author's contribution:}

PR, NJ - Contributed the complete process of this study, Participate in concept design, review of literature, data collection, interpret results, statistical analysis and interpretation, preparing manuscript, first draft, critical revision of manuscript.

\section{Work Attributed to:}

Department of Pediatric, Department MGM Medical College, Indore M.P.

Orcid ID:

Dr. Pramila Ramawat - (1) https://orcid.org/0000-0002-3172-1391

Dr. Nilesh Jain - (1) https://orcid.org/0000-0001-5336-3989 